\title{
CCL5 secreted from bone marrow stromal cells stimulates the migration and invasion of Huh7 hepatocellular carcinoma cells via the PI3K-Akt pathway
}

\author{
HUILI BAI ${ }^{1 *}$, YAGUANG WENG ${ }^{1 *}$, SHUNJIE BAI ${ }^{1-3}$, YINGJIU JIANG $^{4}$, BAOLIN LI $^{1}$, FANG HE $^{1}$, \\ RUYI ZHANG ${ }^{1}$, SHUJUAN YAN ${ }^{1}$, FANG DENG $^{1}$, JING WANG ${ }^{1}$ and QIONG SHI ${ }^{1}$ \\ ${ }^{1}$ Key Laboratory of Diagnostic Medicine Designated by the Chinese Ministry of Education, ${ }^{2}$ Institute of Neuroscience, \\ ${ }^{3}$ Chongqing Key Laboratory of Neurobiology and ${ }^{4}$ The First Affiliated Hospital, \\ Chongqing Medical University, Chongqing 400016, P.R. China
}

Received January 18, 2014; Accepted April 14, 2014

DOI: 10.3892/ijo.2014.2421

\begin{abstract}
Bone metastases from hepatocellular carcinoma (HCC) seem to be increasing. Previous studies showed that soluble factors secreted by host cells and direct cell-tocell interactions contributed to the preferential metastasis and growth of cancer cells in bone, while the underlying mechanism(s) of the metastasis of HCC in the bone are poorly understood. Here, we determined the effect of HS-5 cells on Huh7 cell proliferation, and investigated the role of CCL5 from HS-5 cells on the development of Huh7 cells. In addition, the underlying mechanisms on the influence in Huh7 cells were investigated. Our results showed that HS-5 cells could promote the proliferation, migration and invasion of Huh7 cells, and inhibited apoptosis. CCL5 downregulation was able to inhibit the effects of HS-5 cells on Huh7 cell migration and invasion via the PI3K-Akt signaling pathway and reduce MMP-2 expression. Therefore, these findings suggest that CCL5 secreted from MSCs can promote the migration and invasion of Huh7 cells and could be an important factor in HCC related to occurrence of bone metastases.
\end{abstract}

\section{Introduction}

Hepatocellular carcinoma (HCC) is a common malignancy, the third cause of cancer-related mortality worldwide (1). Frequent intrahepatic and extrahepatic metastases are the main factors contributing to the high mortality of HCC patients (2).

Correspondence to: Dr Qiong Shi, Department of Laboratory Medicine, Chongqing Medical University, 1 Yixueyuan Road, Yuzhong, Chongqing 400016, P.R. China

E-mail: anniesq8718@aliyun.com

*Contributed equally

Key words: CCL5, marrow stromal cells, bone metastases, hepatocellular carcinoma, microenvironment
Previously, bone metastases were considered less common in patients with HCC. However, due to the improved duration of intrahepatic primary tumors, bone metastases from HCC seem to be increasing and frequently recorded $(3,4)$. Thus, early diagnosis of bone metastasis plays a pivotal role in the therapeutic regimen and the assessing prognosis (5). It is generally considered that cancer is a dynamic exchange between tumor cells and surrounding host cells, as first proposed in 1889 by Stephen Paget who indicated that the seeding of metastatic cancer cells depended on the host organ microenvironment (the 'seed and soil' concept) (6). To our knowledge, soluble factors secreted by host cells and direct cell-to-cell interactions are deemed to contribute to the preferential metastasis and growth of cancer cells in bone $(7,8)$, however, the underlying mechanism of metastasis of $\mathrm{HCC}$ in the bone is poorly understood.

Marrow/mesenchymal stromal cells (MSCs) play a major role of tumor stroma in bone microenvironment and have an effect on growth and metastasis of human malignancies. However, the exact effect of MSCs on tumor growth and progress is still under debate (9). The contradiction exists in some cancer cells, including melanoma (10,11), breast cancer (12), colon cancer (13), Kaposi's sarcoma (14), and prostate cancer (15). In HCC, some studies demonstrated that MSCs contributed to tumor progression (16-18), several other studies demonstrated that MSCs could inhibit metastasis (19-21) and tumorigenesis (22). MSCs in HCC metastasis remains controversial. MSCs secrete various cytokines that have both paracrine and autocrine functions, besides MSCs are able to generate a direct effect through intercellular signaling via physical contact with tumor cells (23).

CCL5 (also known as regulated upon activation, normally $\mathrm{T}$ cell expressed and secreted, or RANTES) belongs to the CC family of inflammatory chemokines and is expressed by many liver and infiltrating cells (24), and interacts with the G-protein coupled receptors CCR1, CCR3 and CCR5. CCL5 is also secreted from tumor or stromal cells, and may act in an autocrine or a paracrine manner on cancer cells to enhance their migration and invasion $(12,25,26)$. It was shown that CCL5 exhibited in vitro migratory and invasive stimulus on HCC 
cells $(27,28)$, but some other studies reported that increased CCL5 expression might be connected with favorable outcomes in some cancer diseases (29,30). However, the effects of CCL5 mediated by HS- 5 cells and detailed mechanisms of Huh7 cell progress are largely unknown, thus, there is an urgent need for increased understanding.

Based on the studies above, we aimed to investigate the effects of CCL5 from HS-5 cells on Huh7 cells, as well as the underlying mechanisms. Our investigation found that HS-5-CM could promote the proliferation, migration and invasion of Huh7 cells, and inhibited apoptosis. CCL5 downregulation inhibited the effects of HS-5 cells on Huh7 cells migration and invasion via PI3K-Akt signaling pathway and reduced MMP-2 expression. These results suggest that MSCs mediated CCL5 promoting migration and invasion of Huh7 cells and it may offer a novel strategy to efficiently inhibit metastasis.

\section{Materials and methods}

Cell culture and reagents. The human hepatocellular carcinoma cell lines Huh7, SMMC-7721, HepG2 and normal human liver cell lines LO2 were kindly provided by Dr Tongchuan $\mathrm{He}$ (University of Chicago Medical Center), and bone marrow stromal cell lines HS-5 were purchased from American Type Culture Collection (ATCC, Manassas, VA). Cells were maintained in Dulbecco's modified Eagle's medium (DMEM, HyClone, USA) supplemented with $10 \%$ fetal bovine serum (FBS, Gibco, USA) and $100 \mathrm{U} / \mathrm{ml}$ streptomycin/penicillin at $37^{\circ} \mathrm{C}$ in $5 \% \mathrm{CO}_{2}$. The primary antibodies used in this study were: rabbit anti-Akt monoclonal antibody, rabbit anti-phosphor-Akt monoclonal antibody, rabbit anti-ERK1/2 monoclonal antibody and rabbit anti-phosphor-ERK1/2 monoclonal antibody and were obtained from Cell Signaling Technology. Rabbit anti-MMP-2 polyclonal antibody was purchased from Immunoway (Immunoway, USA). Mouse anti- $\beta$-actin monoclonal antibody was purchased from Santa Cruz Biothechnology. Secondary antibodies included HRP-conjugated goat anti-mouse IgG antibody and anti-rabbit IgG antibody were purchased from Zhongshan Goldenbridge Biotechnology. Specific inhibitors of PI3K (LY294002) and ERK1/2 (PD98059) were obtained from Cell Signaling Technology. CCL5 neutralization antibody was purchased from Peprotech.

Collection of HS-5 cell conditioned medium (HS-5-CM). HS-5 cells were plated in a $100 \mathrm{~mm}^{2}$ culture dish at a density of $80 \%$, for $6 \mathrm{~h}$, for cells adherence, culture medium was changed to serum-free DMEM (SF DMEM). The culture supernatant was harvested every day for 3 days and then all medium were pooled, and sterile filtered. The HS-5-CM was stored at $-20^{\circ} \mathrm{C}$.

Co-culture experiment. The co-culture experiment was set up in duplicates using 6-well Transwell inserts (Millipore, USA) with $0.4 \mu \mathrm{m}$ pore size. In Transwell chamber, HS-5 cells were plated at the density of $10^{5}$ cells/well in $1 \mathrm{ml}$, whereas Huh7 or SMMC-7721 or LO2 cells were plated in the 6-well plates at the density of $2 \times 10^{5}$ cells/well in $2 \mathrm{ml}$. Cells were left to adhere for $6 \mathrm{~h}$ before being put together in the SF DMEM for 3 days, and cells alone were used as control.
Cell viability assay. MTT [3-(4, 5-dimethylthiazol-2-yl)-2, 5-diphenyltetrazolium bromide] assay was used to detect cell viability. A total of $2 \times 10^{3}$ cells/well were cultured in 96-well plates and treated with fresh DMEM, 50\% HS-5-CM (CM:DMEM=1:1) or $100 \%$ HS-5-CM containing $1 \%$ FBS for 24, 48 and $72 \mathrm{~h}$. After the indicated hours of culture, the MTT reagent (Sigma, St. Louis, MO, USA) was added (20 $\mu \mathrm{l} /$ well), and incubated for $4 \mathrm{~h}$ at $37^{\circ} \mathrm{C}$. Dimethyl sulfoxide was added to dissolve the formazan product for $10 \mathrm{~min}$ at room temperature. Finally, the absorbance was measured daily for the next three days at $492 \mathrm{~nm}$ using a microplate reader. Each group was done in sextuplicate, and the overall experiment was repeated three times.

Flow cytometry. Cell cycle and cell apoptosis analysis were assessed by flow cytometry. Cells were divided into 3 groups: i) control group, Huh7 cells; ii) co-culture group, Huh7 cells were co-cultured with HS-5 cells; and iii) HS-5-CM group, Huh7 cells were treated with HS-5-CM. In brief, cells were seeded into 6 -well plates at a density of $2 \times 10^{5}$ cells/well. Every experiment was repeated twice in each group. Cells were harvested, re-suspended in $1 \mathrm{ml}$ cold PBS. Samples were fixed with pre-cold $75 \%$ enthanol for $1 \mathrm{~h}$ at $4^{\circ} \mathrm{C}$ by cell cycle assay, and other samples were added using propidium iodide (PI) and FITC-Annexin V for cell apoptosis analysis according to the manufacturer's protocol (Invitrogen, USA). Respectively, data were analyzed using FACsorter (Becton Dickinson, CA, USA).

Wound-healing assay, Transwell chamber migration and invasion assay. For wound-healing assay, cells were grown to $95 \%$ confluence and the monolayer was scratched with a pipette tip, and then culture medium was replaced with fresh DMEM or 50\% HS-5-CM or 100\% HS-5-CM containing $1 \%$ FBS. Cells that migrated into the scratched area were compared using bright field microscopy at $48 \mathrm{~h}$. Cell migration and invasion assay were performed by 24 -well Transwell chambers ( $8 \mu \mathrm{m}$ pore size, Millipore) without or with ECM gel (Sigma). Briefly, cells $\left(5 \times 10^{4} / 400 \mu l\right)$ in SF DMEM were seeded onto the upper chambers, and fresh DMEM or $50 \% \mathrm{HS}-5-\mathrm{CM}$ or $100 \% \mathrm{HS}-5-\mathrm{CM}(600 \mu \mathrm{l} /$ well $)$ containing $20 \%$ FBS added to the lower chambers. After $24 \mathrm{~h}$, cells that migrated to the underside of the filter were fixed with methanol and stained with hematoxylin and eosin (H\&E), and counted by brightfield microscopy. All the experiments were repeated three times.

Animal studies. The in vivo experiments were performed in accordance with the guidelines established by the Animal Care and Use Committee, of Chongqing University Laboratory Animal Research. The 4-6-week old male NOD/ SCID mice were randomly divided into 2 groups $(n=4 /$ group), respectively, and were injected subcutaneously with a mixture of equal number of HS-5 cells $\left(3 \times 10^{6}\right)$ and Huh7 cells $\left(3 \times 10^{6}\right)$ or with Huh7 cells $\left(6 \times 10^{6}\right)$ alone. Tumor volume was measured every 10 days with vernier calipers, and calculated in $\mathrm{mm}^{3}$ as $\mathrm{ab}^{2} / 2$, where a and $\mathrm{b}$ represent the largest and smallest tumor diameters, respectively. The mice were sacrificed after 70 days, and tumor tissues, livers and lungs were collected and stained using H\&E in order to examine the histopathology. 
Table I. The sequence of PCR primers for each gene.

\begin{tabular}{lll}
\hline Genes & \multicolumn{1}{c}{ Forward primers $\left(5^{\prime} \rightarrow 3^{\prime}\right)$} & Reverse primers $\left(5^{\prime} \rightarrow 3^{\prime}\right)$ \\
\hline CXCL12 & TGAGCTACAGATGCCCATGC & TTCTCCAGGTACTCCTGAATCC \\
CXCR4 & ACGCCACCAACAGTCAGA & ACAACCACCCACAAGTCA \\
CXCR7 & TTATCGCTGTCTTCTACTTCC & CTTGGTGAGCCCTGTTTT \\
CX3CL1 & AAGGAGCAATGGGTCAAGG & ACGGGAGGCACTCGGAAA \\
CX3CR1 & CACCGACATTTACCTCCT & TTGGCTTTCTTGTGGTTCTT \\
CXCL8 & ACTCCAAACCTTTCCACC & CTTCTCCACAACCCTCTG \\
CXCR1 & AAAATGGCGGATGGTGTT & GACGAAGAAGTGTAGGAGGT \\
CCL5 & TTGCTACTGCCCTCTGCG & CACTTGGCGGTTCTTTCG \\
CCR1 & CCCTTGGAACCAGAGAGAAG & CAAACTCTGTGGTCGTGTCA \\
CCR3 & TCGTTCTCCCTCTGCTCG & AGATGCTTGCTCCGCTCA \\
CCR5 & CTGCTACTCGGGAATCCTAAA & CATAGCTTGGTCCAACCTGTTA \\
MMP-2 & CTACGATGATGACCGCAAGT & CAGTCCGCCAAATGAACC \\
MMP-7 & GGAGGAGATGCTCACTTCGAT & AGGAATGTCCCATACCCAAAGA \\
MMP-9 & GGGACGCAGACATCGTCATC & TCGTCATCGTCGAAATGGGC \\
\hline
\end{tabular}

Total RNA isolation, $R T-P C R$, and real-time quantitative $P C R(q R T-P C R)$ analysis. Huh7 cells were co-cultured with HS-5 cells or alone in SF DMEM for 3 days, total RNA was isolated using TRIzol Reagents (Invitrogen) according to the manufacturer's instructions. Total RNA $(2 \mu \mathrm{g})$ was used to generate cDNA templates for reverse transcriptase-PCR. Touchdown PCR analysis determined the gene expression levels and was performed by using the following program: $95^{\circ} \mathrm{C} \times 2 \mathrm{~min}$ for one cycle, 10 cycles at $92^{\circ} \mathrm{C} \times 20 \mathrm{sec}$, $65^{\circ} \mathrm{C} \times 30 \mathrm{sec}$, and $70^{\circ} \mathrm{C}$ x $40 \mathrm{sec}$ with a decrease of one degree per cycle, and 25 cycles at $92^{\circ} \mathrm{C}$ x $20 \mathrm{sec}, 55^{\circ} \mathrm{C}$ x $30 \mathrm{sec}$, and $70^{\circ} \mathrm{C}$ x $40 \mathrm{sec} .70^{\circ} \mathrm{C}$ x $5 \mathrm{~min}$ for one cycle. Real-time PCR was run in the Rotor-Gene 6000 Real-Time PCR machine (Corbett Research, Australia) using SYBR Premix Ex Taq (Takara) with the following protocol: initial activation of HotStar Taq DNA polymerase at $95^{\circ} \mathrm{C}$ for $10 \mathrm{~min}$, then 45 cycles of $95^{\circ} \mathrm{C}$ for $5 \mathrm{sec}$ and $60^{\circ} \mathrm{C}$ for $20 \mathrm{sec}$. GAPDH was used as an internal control. The primer efficiency was confirmed to be high (>90\%) and comparable (Table I). Data were analyzed according to the $2^{-\Delta \Delta C t}$ method. The expression levels of mRNA were normalized to GAPDH.

Enzyme-linked immunosorbent assay (ELISA). To determine quantification of the levels of CCL5 secreted in the supernatants from co-culture or non co-culture, the culture medium was collected and detected by using ELISA Kits (RayBiotech, ELH-RANTES-001), according to the manufacturer's protocol. Briefly, samples were added to the coated wells with CCL5 mAb of 96-well plates and incubated for $2.5 \mathrm{~h}$ at room temperature, washed four times and then incubated with an HRP-linked streptavidin solution for $30 \mathrm{~min}$ at room temperature in the dark. The absorbance was then measured at $450 \mathrm{~nm}$ on the microplate reader (Sunrise Remote, Switzerland) immediately. All the experiments were repeated for three times.
Gelatin zymography of MMP-2 and MMP-9 activity. Equal amount of protein from Huh7 cells co-cultured with HS-5 cells or alone were mixed with SDS buffer, and were added onto a $5 \%(\mathrm{w} / \mathrm{v})$ stacking polyacrylamide gel and separated on a $10 \%(\mathrm{w} / \mathrm{v})$ polyacrylamide gel containing $1.0 \mathrm{mg} / \mathrm{ml}$ porcine gelatin (Sigma) for the detection of MMP-2 and MMP-9 activity. After electrophoresis, gels were washed twice for $40 \mathrm{~min}$ in $2.5 \%$ Triton $\mathrm{X}-100$ (Sigma) to remove SDS, and incubated for $42 \mathrm{~h}$ at $37^{\circ} \mathrm{C}$ in $50 \mathrm{mM}$ Tris- $\mathrm{HCl}(\mathrm{pH} \mathrm{7.6)}$ containing $150 \mathrm{mM} \mathrm{NaCl}, 10 \mathrm{mM} \mathrm{CaCl}_{2}$ and $0.02 \%$ Brij-35, and gels were stained for $3 \mathrm{~h}$ in $45 \%$ methanol/10\% acetic acid containing $0.5 \%$ Coomassie brilliant Blue R-250 (w/v). Finally, destained with a solution containing 5\% acetic acid until clear bands of gelatinolysis appeared on a dark background, proteolytic activity was detected as clear bands on a blue backgroup of the Coomassie Blue staining gel.

Western blot analysis. Western blot was done using standard protocols. In brief, Huh7 cells co-cultured or non co-cultured were washed three times with cold PBS and lysed in RIPA lysis buffer, and cell lysate was denatured after boiling. The protein concentration was measured according to NanoDrop100 UV-Vis Spectrophotometer (Thermo Scientific, USA). Equal amount of proteins were loaded onto $10 \%$ SDS-PAGE gels, and transferred subsequently onto PVDF membranes. After blocking with 5\% BSA (Bovine Serum Albumin, Solarbio) in TBST, the membranes were probed with the primary antibody, and followed by incubation with a secondary antibody conjugating with horseradish peroxidase. Protein levels were quantified with SuperSignal West Pico Chemiluminescent Substrate kit.

Statistical analysis. Results are presented as mean \pm standard deviation (SD). Comparisons were made using independent sample Student's t-test in GraphPad prism 5. Statistical significance is indicated as $\mathrm{p}<0.05$. 


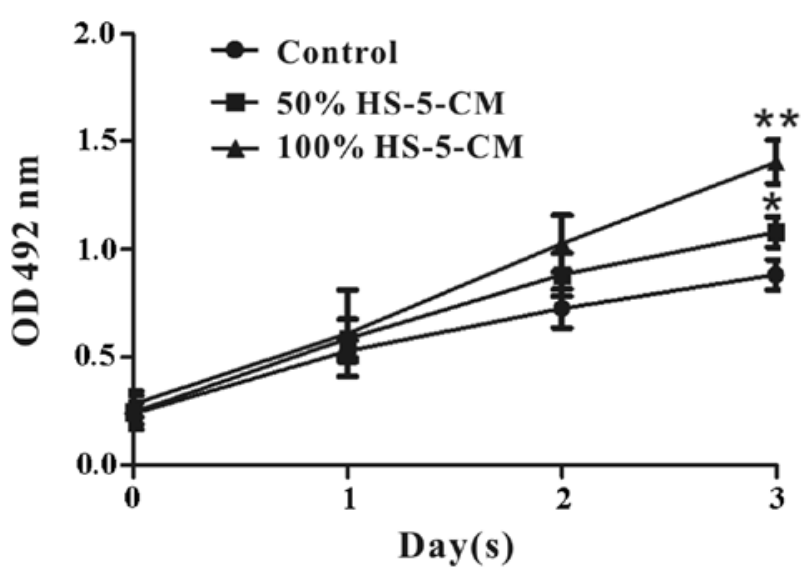

Figure 1. HS-5 cells increase Huh7 cells viability in vitro. Cell viability as measured by MTT assay. Huh7 cells were treated with fresh DMEM or $50 \%$ HS-5-CM or $100 \%$ HS-5-CM for 3 days, fresh DMEM was used as control group. The results represent the mean absorbance \pm SD of three independent experiments. ${ }^{*} \mathrm{p}<0.05$ or ${ }^{* *} \mathrm{p}<0.01$ vs. control.

\section{Results}

HS-5 cells stimulate proliferation and suppress apoptosis of Huh7 cells in vitro. The effects of HS-5 cells on Huh7 cell viability in vitro were evaluated by MTT assay. It revealed that Huh7 cell viability treated with HS-5-CM increased obviously and time-dependently compared with control (Fig. 1). To further investigate the mechanisms of HS-5 cell-induced proliferation of Huh7 cells, flow cytometry was performed to measure the cell cycle. In order to study how HS-5 cells affect Huh7 cell growth in tumor microenvironment, we adopted two ways to culture Huh7 cells: co-cultured with HS-5 cells, and treatment with HS-5-CM, subsequent experiments were done using 100\% HS-5-CM. Respectively, Huh7 cells in co-culture group $(37.85 \pm 1.52 \%)$ and in HS-5-CM group $(29.56 \pm 2.03 \%)$ were at $\mathrm{S}$ phase of cell cycle at day 3, which was significantly higher than the control $(8.96 \pm 2.34 \%)$ (Fig. 2A). These two ways had different degrees of increase in $\mathrm{S}$ phase, but the data demonstrated that HS-5 cells could promote Huh7 cell proliferation.

The proportion of Huh7 cells undergoing apoptosis was determined by flow cytometry analysis. After 3 days, the data showed the apoptosis ratio (early + late) of Huh7 cells in co-culture group was approximately $6.50 \%$, and it was significantly decreased compared to the control group, although HS-5-CM was not distinct in decreasing the apoptotic percentage of Huh7 cells, the small change implied that HS-5 cells could suppress Huh7 cell apoptosis (Fig. 2B).

HS-5 cells significantly promote migration and invasion of Huh7 cells in vitro. As cell migration and invasion abilities are important determinants in the progression of HCC metastasis, the potential to migrate was tested in the commonly used wound-healing assay. After cultured with HS-5-CM for $48 \mathrm{~h}$, the motility of Huh7 cells was significantly accelerated compared with control, especially in 100\% HS-5-CM (Fig. 3A). Transwell assay was carried out to verify the migration potency. In line with the wound-healing experiment, it demonstrated that
$100 \%$ HS-5-CM prominently increased the migration potency of Huh7 cells compared to the control (Fig. 3B). Applying Transwell assay to test the invasion property of Huh7 cells for $24 \mathrm{~h}$, respectively, the number of transmembrane cells in 50\% HS-5-CM group and 100\% HS-5-CM group was remarkably increased compared to the control group (Fig. 3C).

HS-5 cells promote tumor growth of Huh7 cells in vivo. A critical experiment for determining whether HS-5 cells affect tumor growth of $\mathrm{HCC}$ is the in vivo tumorigenicity assay. Therefore, we sought to validate our in vitro findings by using an in vivo model. It found that HS-5 cells accelerated the growth of Huh7 tumors, up to 20 days, there was no significant difference in the two groups, while the tumor volumes became palpable after 20 days, the Huh7 group grew from 150 to $2,522.4 \mathrm{~mm}^{3}$ and the co-culture group grew from 200 to $3,321.8 \mathrm{~mm}^{3}$ (Fig. 4A and B). These results were consistent with the in vitro observation that HS-5 cells markedly promoted Huh7 cells growth. H\&E staining showed no variance in heterogeneity between the two groups (Fig. 4C). Tumor cells were not found in the liver and lung tissues between the two groups (data not shown).

Co-culture with Huh7 cells increases CCL5 expression in HS-5 cells. The molecular mechanisms of these pro-metastatic impacts in tumor microenvironment are still unclear. To investigate whether it is mediated by soluble factors secreted from HS- 5 cells in the capacity of migration and invasion, we identified several chemokines by RT-PCR using RNA prepared from HS-5 cells co-cultured with Huh7 cells or alone at day 3. It was found that CXCL12, CX3CL1, CXCL8, CCL5 mRNA levels were upregulated in HS-5 cells after co-culture, among which CCL5 showed the highest level of increase (Fig. 5A). We also examined these chemokine special receptor mRNAs in Huh7 cells. RT-PCR assay showed that CXCR4 and CCR5 mRNA expression was increased, and CX3CR1 mRNA was decreased in Huh7 cells co-cultured with HS-5 cells compared with Huh7 cells alone at day 3 (Fig. 5B).

To confirm the change on CCL5 expression by qRT-PCR and ELISA assay. qRT-PCR analysis demonstrated that CCL5 mRNA expression had an approximate 5-fold increase in HS-5 cells co-cultured with Huh7 cells compared with HS-5 cells alone at day 3 (Fig. 5C). In accordance with CCL5 mRNA level, ELISA assay revealed that co-culture specifically increased CCL5 protein level more than 3-fold compared with the secretion from Huh7 cells or HS-5 cells (Fig. 5D).

ELISA assay also verified that the change of CCL5 upregulation was not an accidental event with SMMC-7721 or HepG2 or LO2 cells. It found that CCL5 protein levels were increased in HS-5 cells co-cultured with SMMC-7721 or HepG2 cells in different degrees, but not with normal liver cells LO2 (Fig. 5E). The aforementioned data illustrated that interaction with HCC and HS-5 cells could increase CCL5 secretion in HS-5 cells.

CCL5 secreted from HS-5 cells promotes Huh7 cell migration and invasion in vitro. Whether HS-5 cells can modulate Huh7 cells progression via CCL5 secretion remains unreported. We took a loss-of-function approach to confirm its impact on Huh7 cells, utilizing anti-CCL5 neutralizing antibody to 
A

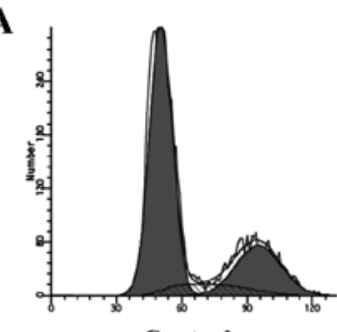

Control

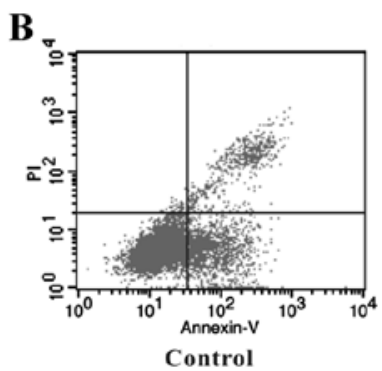

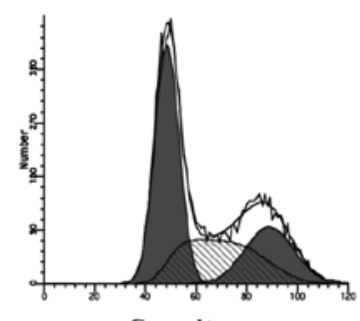

Co-culture

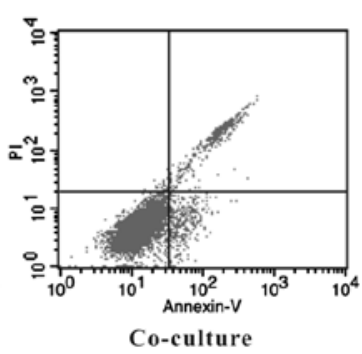

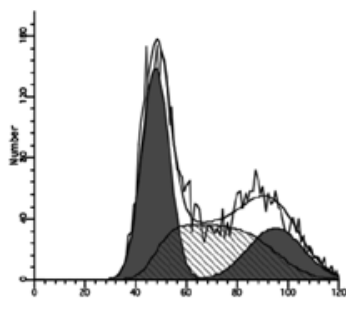

HS-5-CM

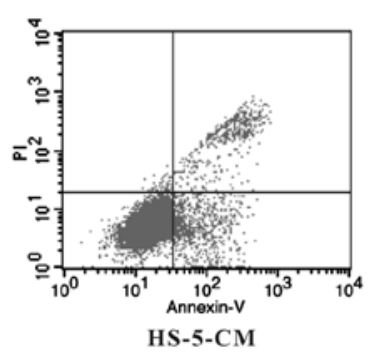

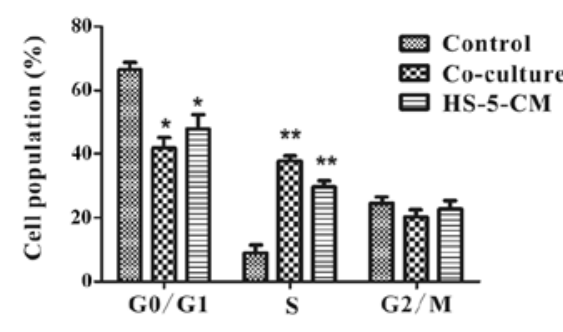

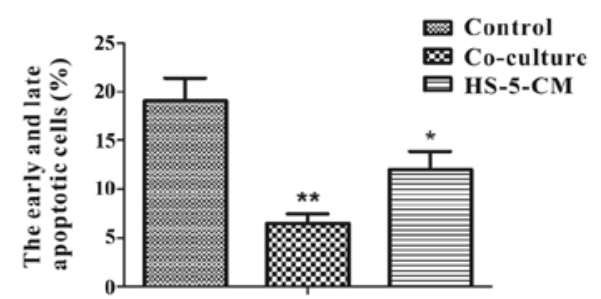

Figure 2. HS-5 cells induce S cell cycle arrest and inhibit apoptosis of Huh7 cells in vitro. (A) Cell cycle and (B) apoptosis as measured by flow cytometry. Huh7 cells were co-cultured with HS- 5 cells or cultured with HS-5-CM for 3 days. Data are presented as mean values \pm SD of three independent measurements. ${ }^{*}<<0.05$ or ${ }^{* *} \mathrm{p}<0.01$ vs. control.
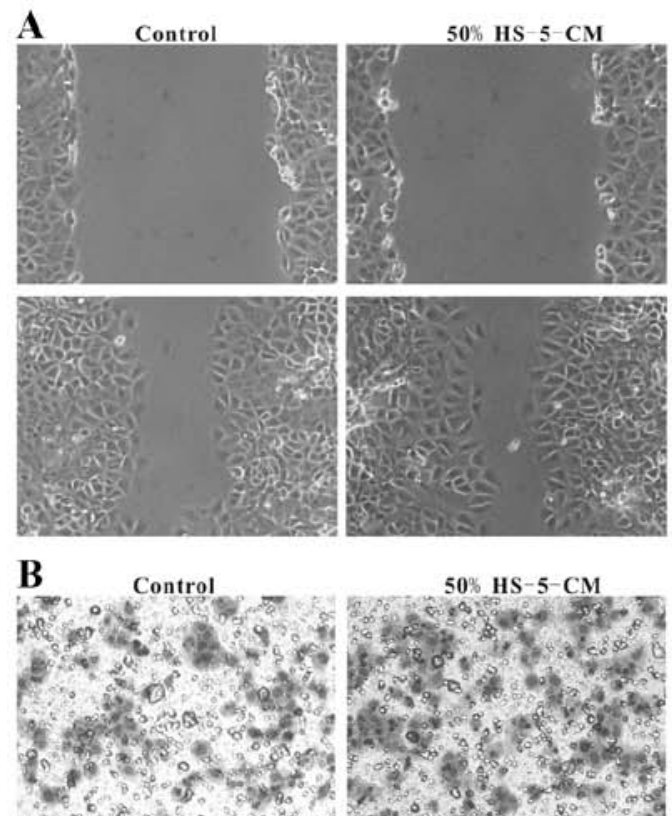

;. 3

\section{C}

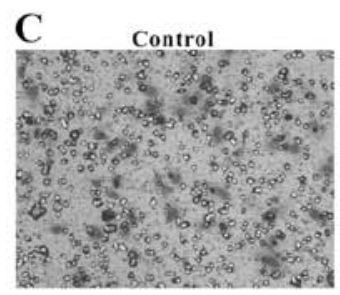

50\% HS- - - CM
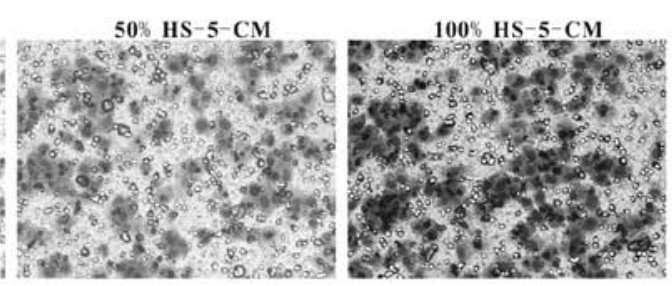

50\% HS- 5- CM

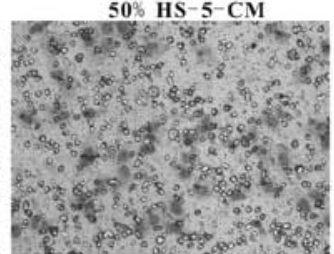

$100 \% \mathrm{HS}-5-\mathrm{CM}$

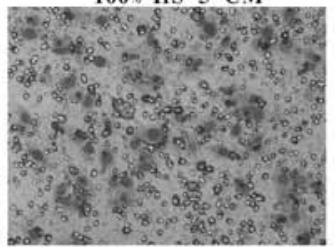

$100 \%$ HS- $5-\mathrm{CM}$

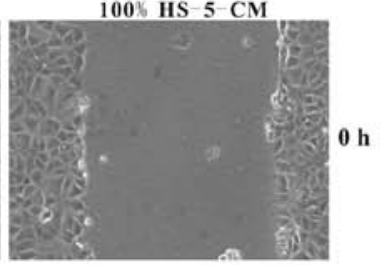

$48 \mathrm{~h}$
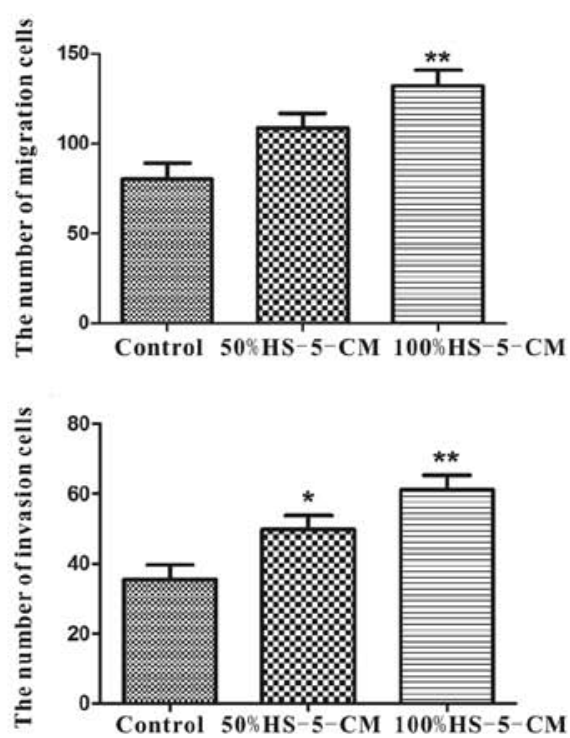

Figure 3. Increase of the migration and invasion of Huh7 cells by HS-5 cells in vitro. (A) Cell migration as measured by wound healing assay. Huh7 cells were treated with fresh DMEM or 50\% HS-5-CM or 100\% HS-5-CM for $48 \mathrm{~h}$. Data are reported as mean values \pm SD of three individual measurements. Magnification, x100. (B) Cell migration and (C) invasion as measured by Transwell assay. Huh7 cells were treated with fresh DMEM or 50\% HS-5-CM or 100\% HS-5-CM for 24 h. Data are reported as mean values $\pm \mathrm{SD}$ of three individual measurements. The quantification data are on the right. Magnification, $\mathrm{x} 150 .{ }^{*} \mathrm{p}<0.05$ or ${ }^{* *} \mathrm{p}<0.01$ vs. control. 
A

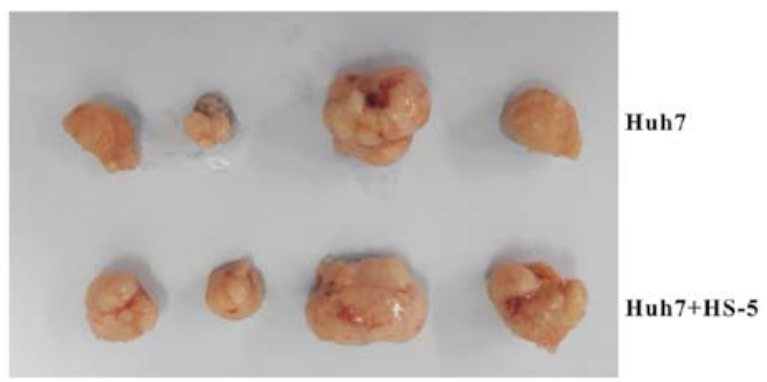

C

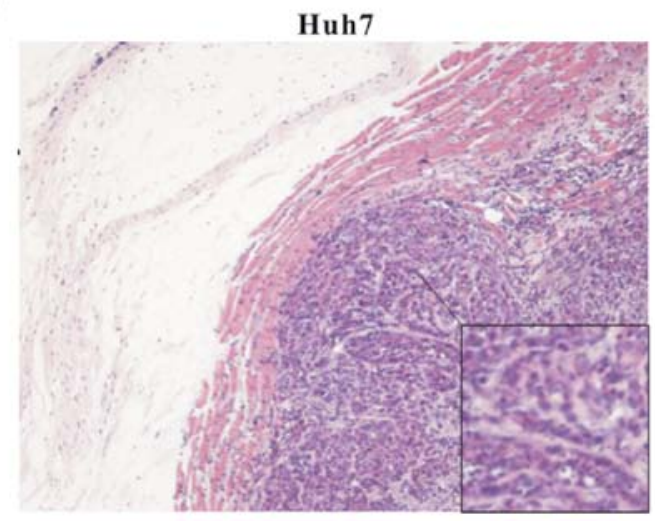

B

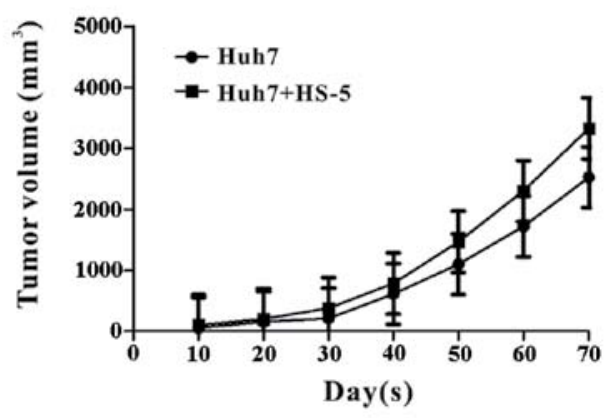

Huh7+HS-5

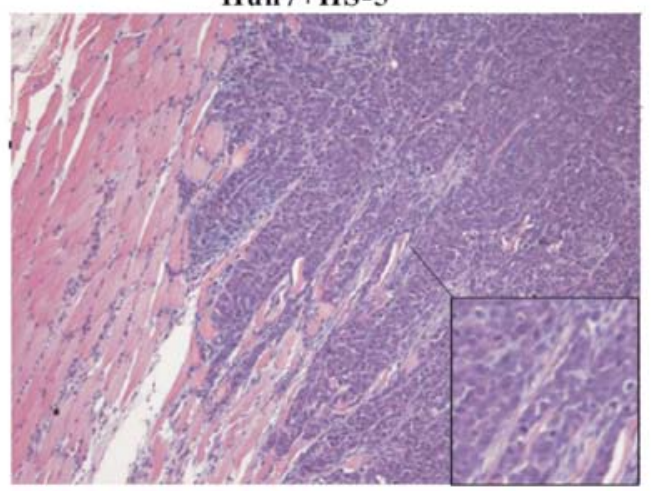

Figure 4. HS-5 cells promote Huh7 cells tumor formation in vivo. (A) Excised tumor tissues from the two groups. (B) Tumor growth curves of the two groups HS-5 cells promoted Huh7 cell tumor growth in vivo. $\mathrm{n}=4$ mice/group, data are reported as mean $\pm \mathrm{SD}$. (C) H\&E staining of tumor tissues. All tumors showed a large nucleus, a high nucleus/cytoplasm ratio, an irregular nuclear shape and variable nuclear size, while no variation in heterogeneity was found between the two groups. The images were taken at x100 magnification.

A

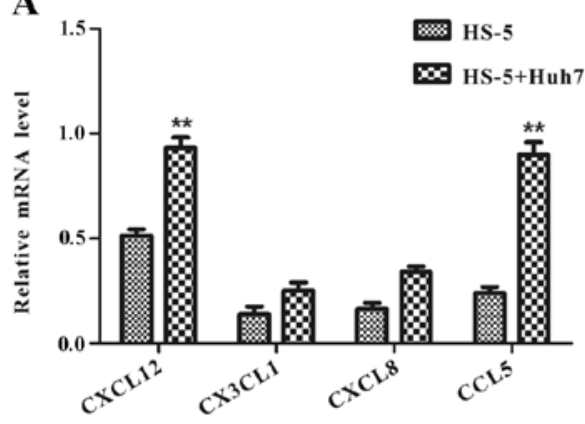

B

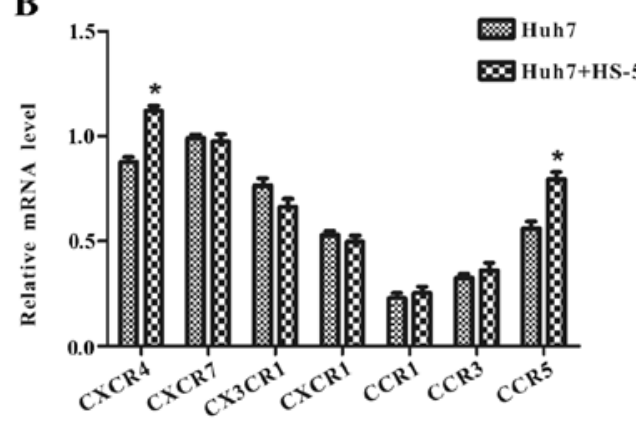

C

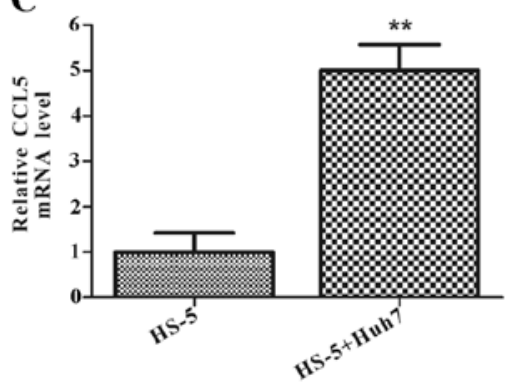

D

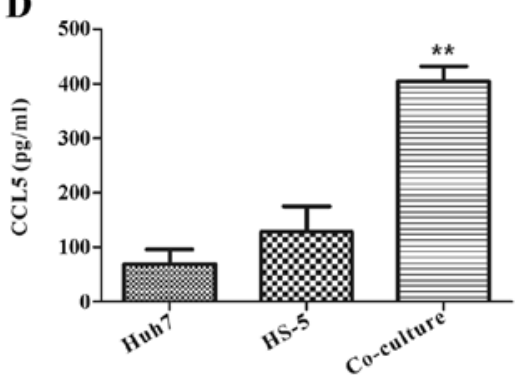

E

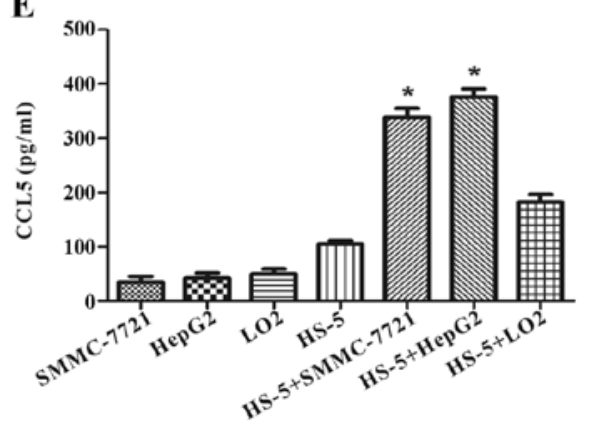

Figure 5. Effects of chemokines and receptors expression after co-culture. RT-PCR assay examined (A) chemokine mRNA levels in HS-5 cells and (B) these special receptor mRNA levels in Huh7 cells after more than 3-day co-culture. Data are reported as mean \pm SD of three individual measurements. "p $<0.05$ vs. Huh7 cells; ${ }^{* *}$ p $<0.01$ vs. HS-5 cells. (C) qRT-PCR assay verified CCL5 mRNA expression in HS-5 cells co-cultured with Huh7 cells or alone at day 3 . Data are reported as mean values $\pm \mathrm{SD}$ of three individual measurements. ${ }^{* *} \mathrm{p}<0.01$ vs. HS -5 cells. (D) CCL5 protein expression as detected by ELISA assay. Co-culture or cells alone culture supernatant at day 3 was collected. Data are reported as mean \pm SD of three individual measurements. ${ }^{* *}<<0.01$ vs. Huh7 or HS- 5 cells alone. (E) CCL5 protein expression in SMMC-7721, HepG2 and LO2 cells, SF culture supernatant from non co-cultured or co-cultured with HS-5 cells at day 3 as detected by ELISA assay. Data are presented as mean \pm SD of three individual measurements * $\mathrm{p}<0.05$ vs. HS- 5 or SMMC-7721 or HepG2 cells alone. 

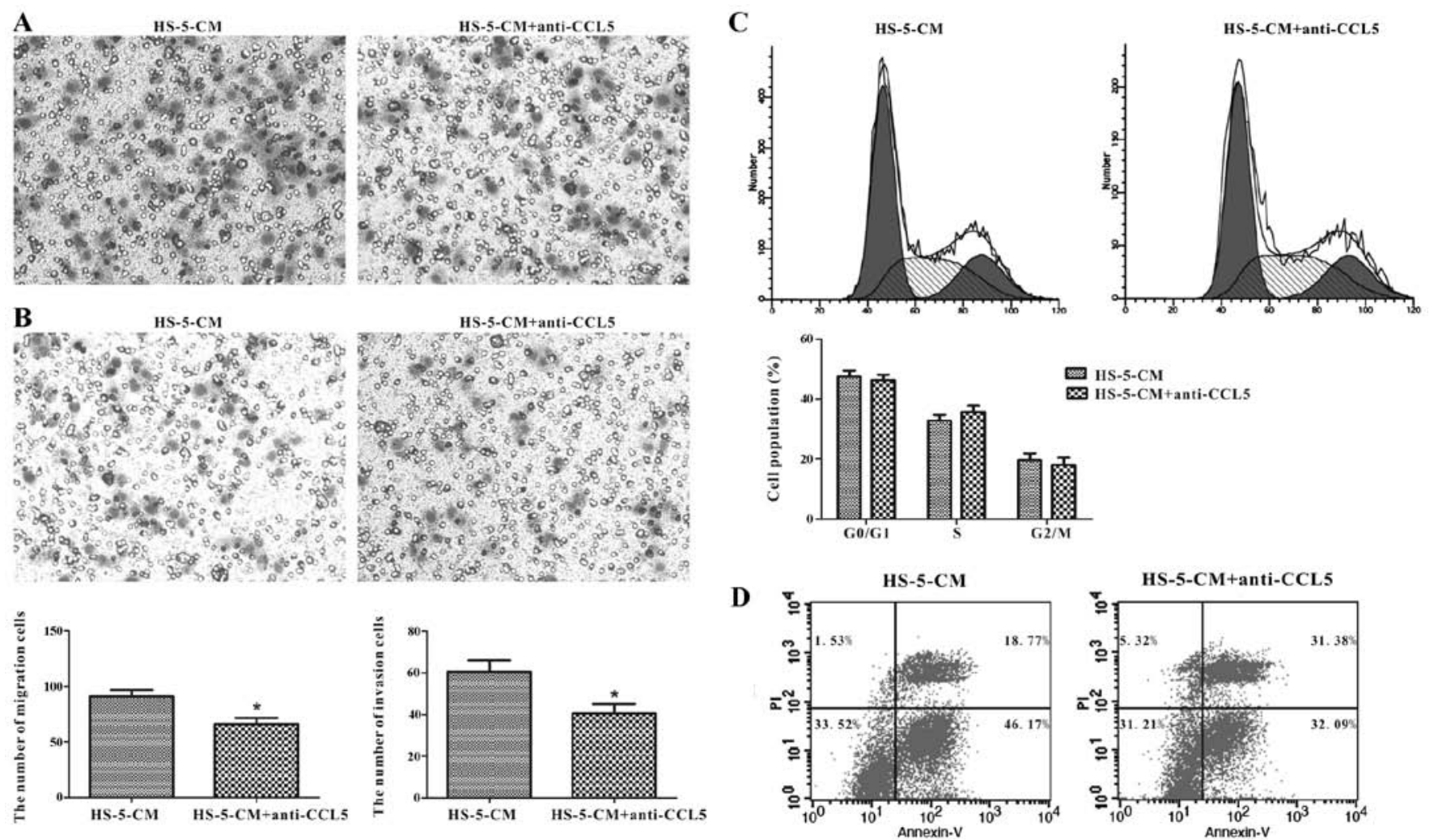

Figure 6. Effect of anti-CCL5 neutralizing antibody in HS-5-CM induced Huh7 cell progression. (A) Cell migration and (B) invasion as measured by Transwell assay. (C) Cell cycle and (D) apoptosis as measured by flow cytometry. Huh7 cells were treated with HS-5-CM containing control (irrelevant) $\mathrm{IgG}$ or anti-CCL5 neutralizing antibody $(1 \mu \mathrm{g} / \mathrm{ml})$ for $24 \mathrm{~h}$. Data are shown as mean \pm SD of three individual measurements (A, left below; B, right below). " $<<0.05$ vs. control IgG. Magnification, $x 150$.

HS-5-CM which was cultured in Huh7 cells for $24 \mathrm{~h}$. We tested the migration and invasion abilities by Transwell assay, and it illustrated that anti-CCL5 neutralizing antibody caused a decrease of $27.47 \%$ in HS-5-CM-induced migration activity of Huh7 cells compared with the control (Fig. 6A). Consistently, Huh7 cell invasion ability was inhibited by $33.06 \%$ compared to the control (Fig. 6B). However, not as imagined, CCL5 downregulation in HS-5-CM did not overtly change proliferation and apoptosis of Huh7 cells (Fig. 6C and D). It was thus possible that CCL5 from HS-5-CM did not play a leading role in Huh7 cell proliferation and apoptosis impact, but in migration and invasion potency.

Effects of CCL5-secreted from HS-5 cells on Huh7 cells via PI3K-Akt signaling pathway. The underlying mechanisms of the interaction with MSCs and HCC within HCC microenvironment remain an enigma, so we concentrated on the mechanisms of HS-5 cells inducing migration and invasion of Huh7 cells. It has been reported that stimulation of MSCs with certain chemokines causes the activation of Akt kinase and ERK1/2 MAP kinase (31). Therefore, we examined the potential changes of Huh7 cells in the presence of HS-5 cells further. The transwell co-culture with HS-5 cells for 3 days, demonstrated by western blot analysis, revealed that Huh7 cells had enhanced expression of p-Akt (Ser473) (Fig. 7A), but not p-ERK1/2 (Fig. 7B). The aforementioned data showed that CCL5 expression was upregulated in HS-5 cells after co-culture (Fig. 5C and D). Previous research showed that CCL5 activated Gai-PI3K-Akt and Gai-MEK-ERK signaling pathways (32). So it was postulated that CCL5 is associated with the activation of p-Akt (Ser473) and p-ERK $1 / 2$ in co-culture system. We applied anti-CCL5 antibody for $24 \mathrm{~h}$ to the co-culture system to evaluate the hypothesis, the data showed the activation of p-Akt (Ser473) was reduced by adding anti-CCL5 neutralizing antibody to Huh7 cells co-cultured with HS-5 cells (Fig. 7A), however, there was no significant change in p-ERK1/2 (Fig. 7B). We next focused on CCL5 expression in response to p-Akt (Ser473) and p-ERK1/2 signaling pathways. Before we investigated the roles of p-Akt (Ser473) and p-ERK1/2 signaling pathways, western blot analysis demonstrated PI3K and ERK1/2 specific inhibitors which, respectively, were LY294002 $(20 \mu \mathrm{M})$ and PD98059 $(10 \mu \mathrm{M})$ could decrease the expression of p-Akt (Ser473) and p-ERK1/2 (Fig. 7A and $\mathrm{B}$ ). Transwell assay illustrated that the migration and invasion of Huh7 cells induced by HS-5-CM were partly reversed by treatment with LY294002 but not by PD98059 (Fig. 7C and D). In addition, ELISA assay demonstrated that LY294002 reduced the secretion of CCL5 in co-culture system (Fig. 7E). Thus, our results illustrated that CCL5 derived from HS-5 cells had a pivotal role in migration and invasion of Huh7 cells via PI3K-Akt signaling pathway.

CCL5 downregulation from HS-5 cells decreases MMP-2 expression in Huh7 cells. Cell movement is involved in the proteolytic activity of MMPs, which regulate the dynamic 

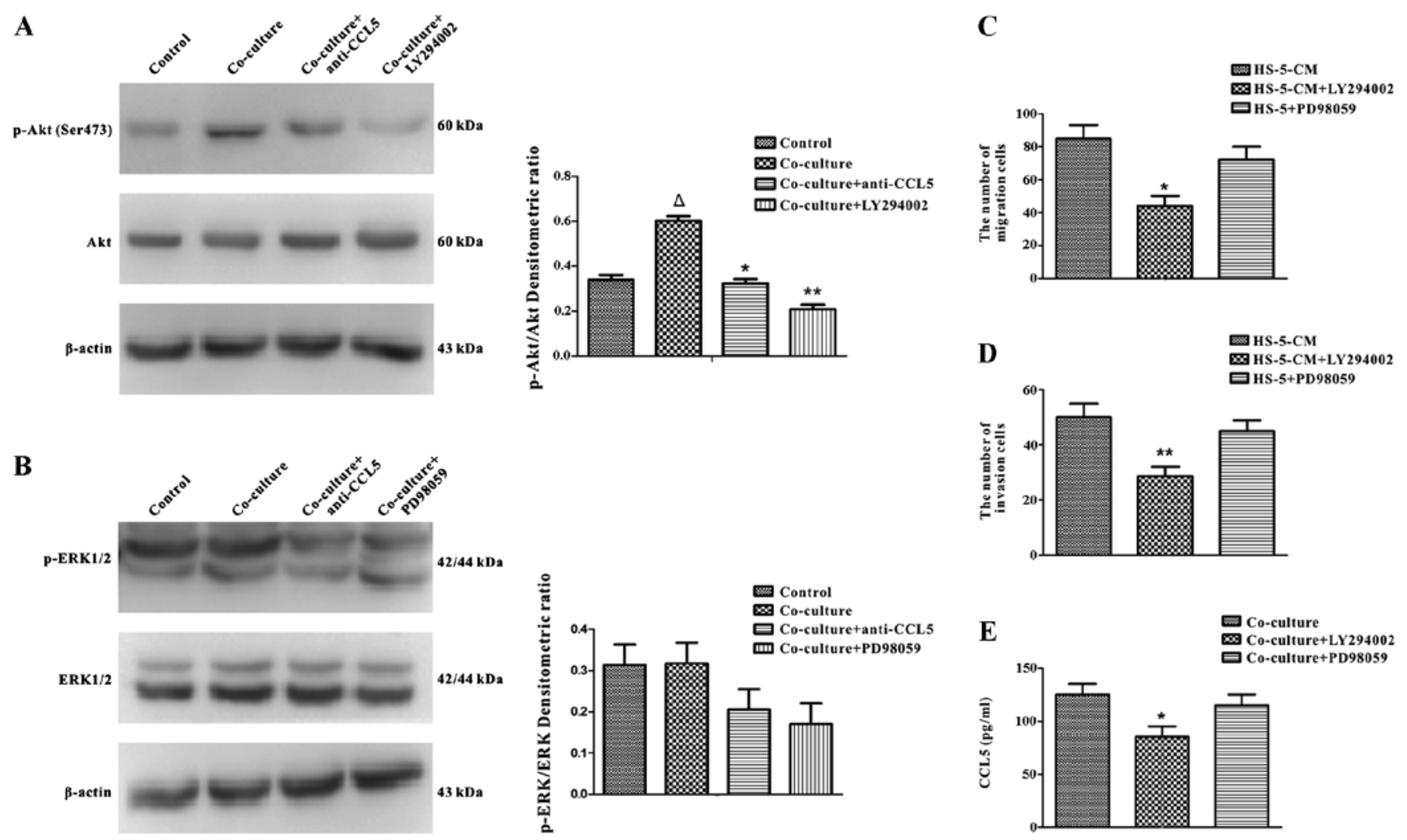

Figure 7. Interaction with the activation of p-Akt (Ser473) and ERK1/2 and the secretion of CCL5. (A) p-Akt (Ser473) protein in Huh7 cells as determined by western blot analysis. Huh7 cells were co-cultured with HS-5 cells for 3 days, and then anti-CCL5 neutralizing antibody (1 $\mu \mathrm{g} / \mathrm{ml})$ or LY294002 (20 $\mu \mathrm{M})$ was added for $24 \mathrm{~h}$, control IgG antibody and DMSO were used as control. Densitometric quantification data are on the right. Data are shown as mean \pm SD of three individual measurements. ${ }^{*} \mathrm{p}<0.05,{ }^{* *} \mathrm{p}<0.01$ vs. co-culture group; ${ }^{\wedge} \mathrm{p}<0.05$ vs. control group. (B) $\mathrm{p}$-ERK1/2 protein in Huh7 cells as determined by western blot analysis. Huh7 cells were co-cultured with HS-5 cells for 3 days, and then anti-CCL5 neutralizing antibody $(1 \mu \mathrm{g} / \mathrm{ml})$ or PD98059 (10 $\mu \mathrm{M})$ was added for $24 \mathrm{~h}$, control IgG antibody and DMSO were used as control. Densitometric quantification data are on the right. Data are shown as mean \pm SD of three individual measurements. (C) Cell migration and (D) invasion as measured by Transwell assay. Huh7 cells were treated with HS-5-CM containing DMSO or LY $294002(20 \mu \mathrm{M})$ or PD98059 $(10 \mu \mathrm{M})$ for $24 \mathrm{~h}$. Data are shown as mean \pm SD of three individual measurements. "p $<0.05$ or ${ }^{* *} \mathrm{p}<0.01 \mathrm{vs}$. HS-5-CM. Magnification, x150. (E) CCL5 protein level in co-culture supernatant as detected by ELISA assay. Huh7 cells were co-cultured with HS-5 cells for 3 days, and then DMSO or LY294002 $(20 \mu \mathrm{M})$ or PD98059 $(10 \mu \mathrm{M})$ was added for $24 \mathrm{~h}$. Data are shown as mean \pm SD of three individual measurements. " $\mathrm{p}<0.05$ vs. co-culture.

ECM (extracellular matrix)-cell and cell-cell interaction during migration (33). High expression of MMPs is related to HCC progression $(34,35)$. We investigated whether CCL5 regulated the levels of MMP-2, MMP-7 and MMP-9 in Huh7 cells co-cultured with HS-5 cells. RT-PCR analysis showed that MMP-2 expression was up-regulated in Huh7 cells co-cultured with HS-5 cells at day 3, extraordinary, MMP-2 mRNA was downregulated through the addition of anti-CCL5 neutralizing antibody. Nonetheless, the expression of MMP-7 and MMP-9 mRNAs remained significantly unchanged (Fig. 8A). To further characterize the effect of CCL5 in MMP expression of Huh7 cells, we applied gelatin zymography analysis to determine expression and enzymatic activities of MMP-2 and MMP-9. The results revealed that treatment of anti-CCL5 neutralizing antibody pointed to a decrease in MMP-2 upregulation of Huh7 cells co-cultured with HS-5 cells, whereas MMP-9 was not detected (Fig. 8B). Consistently, western blot assay confirmed that anti-CCL5 neutralizing antibody could reduce MMP-2 protein upregulation mediated by HS-5 cells in Huh7 cells (Fig. 8C). The data indicated that CCL5 downregulation from HS-5 cells decreased MMP-2 expression in Huh7 cells.

\section{Discussion}

HCC invasion and metastasis are very strongly related to cancer patient survival, but the detailed mechanisms are still unknown (36). Advanced HCC patients presenting with bone metastases are different from breast and prostate cancer patients, particularly in liver function impairment, prognosis and available effective treatments (37). Cirrhosis is an independent prognostic factor for osteoporosis (38). Bone marrow is the most common source of MSCs, which are found to take part in tumor microenvironment that mediates tumor cell progress. However, crosstalk of the tumor-MSCs is complicated, the controversy on the effects of MSCs on the tumor cell progression remains to be debated, especially in HCC. Herein, we adopted HS-5-CM to eliminate the interaction with HCC cells, and it demonstrated that HS- 5 cells could promote proliferation, migration and invasion of Huh7 cells in vitro, and the increase of proliferation was verified by the in vivo results. Our results are consistent with a large proportion of research $(16,17,20)$. However, the tumor metastasis in liver and lung regions were not found, demonstrating that Huh7 cell invasion ability is limited in vivo. Despite the above, some reports 

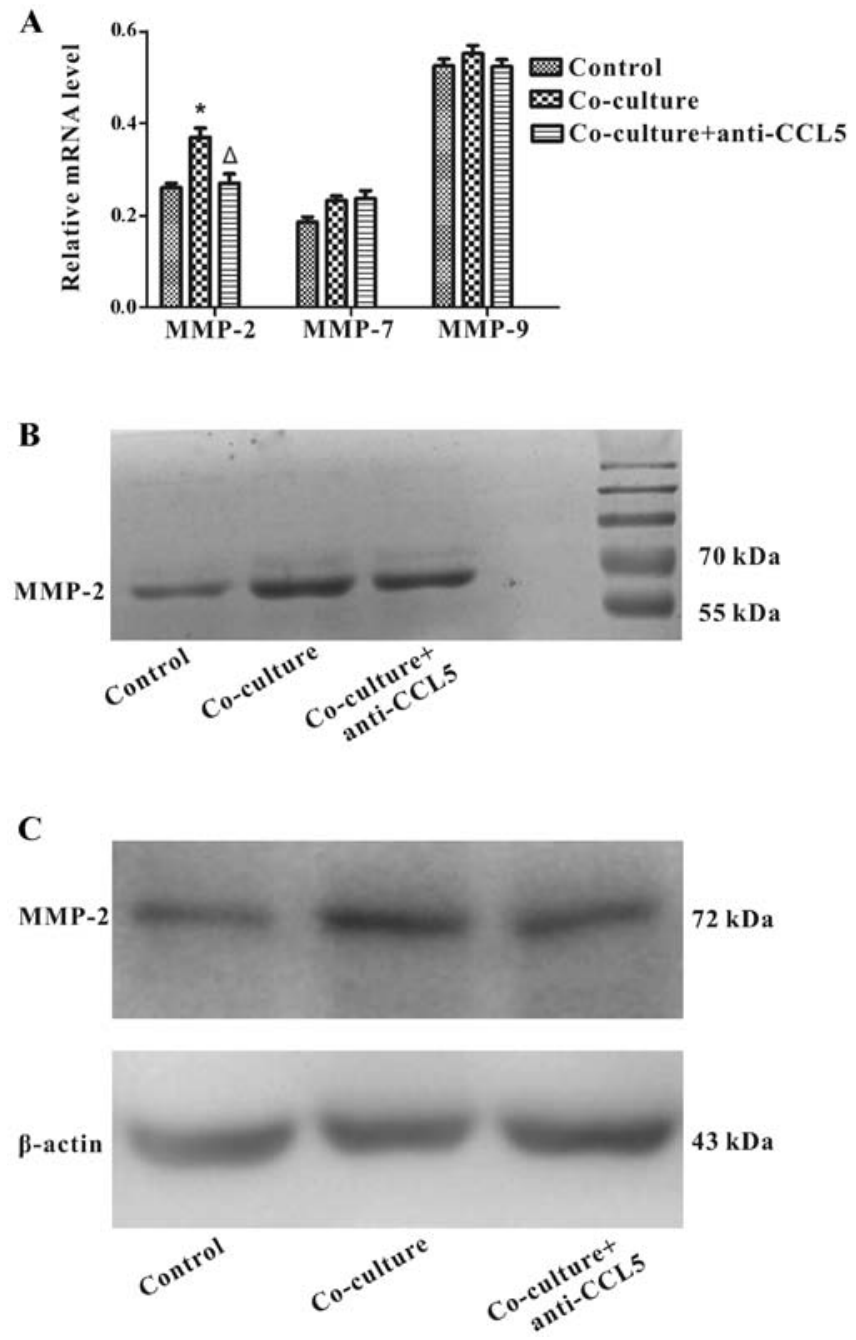

Figure 8. Expression of MMPs in Huh7 cells. (A) MMP mRNA levels in Huh7 cells as showed by RT-PCR analysis. (B) MMP-2 (72 kDa) protein as showed by gelatin zymography analysis. (C) MMP-2 protein level as confirmed by western blot assay. Huh7 cells were co-cultured with HS-5 cells for 3 days, and then control IgG or anti-CCL5 antibody $(1 \mu \mathrm{g} / \mathrm{ml})$ was added for $24 \mathrm{~h}$. Data are shown as mean $\pm \mathrm{SD}$ of three individual measurements. "p $<0.05$ vs. control; ${ }^{\wedge} \mathrm{p}<0.05$ vs. co-culture.

stated that MSCs could inhibit HCC cell growth (22,39). It is proposed that the time of MSCs introduction into tumors might be a critical factor for the contradicting results (9). In this study, we consider that MSCs are helpful for HCC progression.

MSC secretions include a complex mixture of cytokines, growth factors and chemokines, which have an influence on cancer cell migration and invasion. In this study, the data determined that in co-culture with Huh7 cells, HS-5 cells expressed an increased level of CCL5. To circumvent variability in cell-cell interaction subsequent experiments were done using conditioned medium from the 'co-culture' cell lines, and it was shown to consistently alter the CCL5 level. To our knowledge, chemokines and receptors play a number of non-redundant roles in tumor progression. Besides, some reports indicate that CCL5 is an effective inducer of tumor cell migration and invasion, such as in breast, colorectal, osteosarcoma and prostate tumor cells, acting through paracrine and autocrine manners (40-44). It was demonstrated that stroma-derived CCL5 was particularly important in inducing pro-malignancy impact in CCR5-expressing breast cancer cells (12). However, in tumor microenvironment, whether HS-5 cells mediated CCL5 plays a pivotal role in HCC migratory and invasion, has not been extensively studied. We found that Huh7 cells revealed a higher level of CCR5 mRNA than CCR1 and CCR3, and an obvious increase in CCR5 mRNA after co-culture. Furthermore, a recent report determined that CCR5 was involved to HCC inflammation (45). CCR5 is more important than CCR1 and CCR3 in HCC progress in our study. Anti-CCL5 neutralization antibody decreased the migration and invasion of Huh7 cells mediated by HS-5-CM. The results indicated that the CCL5/CCR5 axis was associated with migration and invasion of Huh7 cells in tumor microenvironment. It cannot be denied that other cytokines play a pivotal role of malignant progression like CXCL12 promoting tumor cell proliferation and survival via paracrine and autocrine mechanisms $(46,47)$. It was proposed that CXCL12 could promote HCC cells migration (48). Nevertheless, in mimicking HCC microenvironment, it cannot be ignored that CCL5-secreted from MSCs is a critical factor in Huh7 cell migration and invasion.

Activation of PI3K contributes to invasion and metastasis of HCC (49). ERK1/2 pathway is connected with the migratory or invasive behavior of a variety of malignancies (50). Thus, whether the progression of HCC induced by MSCs is involved in the PI3K/Akt and ERK1/2 signaling pathways has not been yet established. In particular, we demonstrated that the PI3K inhibitor LY294002 antagonized enhancement in migration and invasion of Huh7 cells, and also reduced CCL5 secretion. However, co-culture did not activate the p-ERK1/2 signaling pathway and ERK1/2 specific inhibitor PD98059 did not reduce the mobility and invasiveness of Huh7 cells. It is possible that ERK1/2 signaling pathway regulates another biological function in HCC microenvironment. It is conceivable that other signaling pathways may synergistically or antagonistically regulate the HCC progress. Our data indicated that PI3K/ Akt signaling pathway could play an important part in CCL5mediated migration and invasion of Huh7 cells.

MMPs play a key role in cancer cell invasion. Some data showed that the expression of MMP-2 increased in hepatic fibrosis (51), others reported that certain cytokines could increase MMP-2 and MMP-9 secretion in human sarcoma cells (52). Xiang et al showed that MMP-2 was an independent prognostic factor for lymph node metastasis in HCC (53). Previous studies showed that CCL5 promoted the expression of MMP-9 in tumor cells $(44,54,55)$. In this study, we demonstrated that HS-5 cells did not elevate MMP-9 expression but MMP-2 expression in Huh7 cells. The results suggest that anti-CCL5 neutralization antibody could depress the secretion of MMP-2 in Huh7 cells. Therefore, MMP-2 may be a CCL5-responsive mediator, and it causes the degradation of ECM, which may lead to subsequent HCC migration and metastasis.

In conclusion, the current observations indicate that HS-5 cells can promote the proliferation, migration and invasion, and inhibit apoptosis of Huh7 cells. Exocrine CCL5 secreted from MSCs promotes migration and invasion of Huh7 cells via PI3K/Akt signaling pathway, and accompanies the MMP-2 upregulation. Hence, CCL5 may be an important factor in HCC with bone metastases. 


\section{Acknowledgements}

We would like to thank Dr Tongchuan He (University of Chicago) for the gift of human hepatocellular carcinoma cell lines and normal human liver cell lines. This study was supported by the National Natural Science Foundation of China (NSFC 31200971), National Ministry of Education Foundation of China (20115503110009) and the 973 Program of the Ministry of Science and Technology of China (2011CB707906).

\section{References}

1. Yang JD and Roberts LR: Hepatocellular carcinoma: A global view. Nat Rev Gastroenterol Hepatol 7: 448-458, 2010.

2. Ma W, Wong CC, Tung EK, Wong CM and Ng IO: RhoE is frequently down-regulated in hepatocellular carcinoma (HCC) and suppresses HCC invasion through antagonizing the Rho/Rho-kinase/myosin phosphatase target pathway. Hepatology 57: 152-161, 2013.

3. Ho CL, Chen S, Yeung DW and Cheng TK: Dual-tracer PET/CT imaging in evaluation of metastatic hepatocellular carcinoma. J Nucl Med 48: 902-909, 2007.

4. Natsuizaka M, Omura T, Akaike T, et al: Clinical features of hepatocellular carcinoma with extrahepatic metastases. J Gastroenterol Hepatol 20: 1781-1787, 2005.

5. Xiang ZL, Zeng ZC, Tang ZY, et al: Chemokine receptor CXCR4 expression in hepatocellular carcinoma patients increases the risk of bone metastases and poor survival. BMC Cancer 9: 176, 2009.

6. Paget S: The distribution of secondary growths in cancer of the breast. 1889. Cancer Metastasis Rev 8: 98-101, 1989.

7. Chung LW, Baseman A, Assikis V and Zhau HE: Molecular insights into prostate cancer progression: the missing link of tumor microenvironment. J Urol 173: 10-20, 2005.

8. Chackal-Roy M, Niemeyer C, Moore M and Zetter BR: Stimulation of human prostatic carcinoma cell growth by factors present in human bone marrow. J Clin Invest 84: 43-50, 1989.

9. Klopp AH, Gupta A, Spaeth E, Andreeff M and Marini F III: Concise review: Dissecting a discrepancy in the literature: do mesenchymal stem cells support or suppress tumor growth? Stem Cells 29: 11-19, 2011.

10. Maestroni GJ, Hertens E and Galli P: Factor(s) from nonmacrophage bone marrow stromal cells inhibit Lewis lung carcinoma and B16 melanoma growth in mice. Cell Mol Life Sci 55: 663-667, 1999.

11. Kucerova L, Matuskova M, Hlubinova K, Altanerova V and Altaner C: Tumor cell behaviour modulation by mesenchymal stromal cells. Mol Cancer 9: 129, 2010.

12. Karnoub AE, Dash AB, Vo AP, et al: Mesenchymal stem cells within tumour stroma promote breast cancer metastasis. Nature 449: 557-563, 2007

13. Lin JT, Wang JY, Chen MK, et al: Colon cancer mesenchymal stem cells modulate the tumorigenicity of colon cancer through interleukin 6. Exp Cell Res 319: 2216-2229, 2013.

14. Khakoo AY, Pati S, Anderson SA, et al: Human mesenchymal stem cells exert potent antitumorigenic effects in a model of Kaposi's sarcoma. J Exp Med 203: 1235-1247, 2006.

15. Zhang C, Soori M, Miles FL, et al: Paracrine factors produced by bone marrow stromal cells induce apoptosis and neuroendocrine differentiation in prostate cancer cells. Prostate 71 157-167, 2011.

16. Hernanda PY,Pedroza-Gonzalez A, van der Laan LJ, et al: Tumor promotion through the mesenchymal stem cell compartment in human hepatocellular carcinoma. Carcinogenesis 34: 2330-2340, 2013.

17. Mizuguchi T, Hui T, Palm K, et al: Enhanced proliferation and differentiation of rat hepatocytes cultured with bone marrow stromal cells. J Cell Physiol 189: 106-119, 2001.

18. Jing Y, Han Z, Liu Y, et al: Mesenchymal stem cells in inflammation microenvironment accelerates hepatocellular carcinoma metastasis by inducing epithelial-mesenchymal transition. PLoS One 7: e43272, 2012.

19. Li GC, Ye QH, Dong QZ, Ren N, Jia HL and Qin LX: Mesenchymal stem cells seldomly fuse with hepatocellular carcinoma cells and are mainly distributed in the tumor stroma in mouse models. Oncol Rep 29: 713-719, 2013.
20. Li GC, Ye QH, Xue YH, et al: Human mesenchymal stem cells inhibit metastasis of a hepatocellular carcinoma model using the MHCC97-H cell line. Cancer Sci 101: 2546-2553, 2010.

21. Niess H, Bao Q, Conrad C, et al: Selective targeting of genetically engineered mesenchymal stem cells to tumor stroma microenvironments using tissue-specific suicide gene expression suppresses growth of hepatocellular carcinoma. Ann Surg 254: 767-775, 2011.

22. Qiao L, Xu Z, Zhao T, et al: Suppression of tumorigenesis by human mesenchymal stem cells in a hepatoma model. Cell Res 18: 500-507, 2008

23. Ho IA, Toh HC, Ng WH, et al: Human bone marrow-derived mesenchymal stem cells suppress human glioma growth through inhibition of angiogenesis. Stem Cells 31: 146-155, 2013.

24. Sahin H, Trautwein C and Wasmuth HE: Functional role of chemokines in liver disease models. Nat Rev Gastroenterol Hepatol 7: 682-690, 2010.

25. Makinoshima $\mathrm{H}$ and Dezawa M: Pancreatic cancer cells activate CCL5 expression in mesenchymal stromal cells through the insulin-like growth factor-I pathway. FEBS Lett 583: 3697-3703, 2009.

26. Luther SA and Cyster JG: Chemokines as regulators of T cell differentiation. Nat Immunol 2: 102-107, 2001.

27. Charni F, Friand V, Haddad O, et al: Syndecan-1 and syndecan-4 are involved in RANTES/CCL5-induced migration and invasion of human hepatoma cells. Biochim Biophys Acta 1790: 1314-1326, 2009

28. Sutton A, Friand V, Papy-Garcia D, et al: Glycosaminoglycans and their synthetic mimetics inhibit RANTES-induced migration and invasion of human hepatoma cells. Mol Cancer Ther 6: 2948-2958, 2007.

29. Liou JM, Lin JT, Huang SP, et al: RANTES-403 polymorphism is associated with reduced risk of gastric cancer in women. J Gastroenterol 43: 115-123, 2008.

30. Kondo T, Ito F, Nakazawa H, Horita S, Osaka Y and Toma H: High expression of chemokine gene as a favorable prognostic factor in renal cell carcinoma. J Urol 171: 2171-2175, 2004.

31. Honczarenko M, Le Y, Swierkowski M, Ghiran I, Glodek AM and Silberstein LE: Human bone marrow stromal cells express a distinct set of biologically functional chemokine receptors. Stem Cells 24: 1030-1041, 2006.

32. Tyner JW, Uchida O, Kajiwara N, et al: CCL5-CCR5 interaction provides antiapoptotic signals for macrophage survival during viral infection. Nat Med 11: 1180-1187, 2005.

33. Bao M, Chen Z, Xu Y, et al: Sphingosine kinase 1 promotes tumour cell migration and invasion via the S1P/EDG1 axis in hepatocellular carcinoma. Liver Int 32: 331-338, 2012.

34. Palagyi A, Neveling K, Plinninger U, et al: Genetic inactivation of the Fanconi anemia gene FANCC identified in the hepatocellular carcinoma cell line HuH-7 confers sensitivity towards DNA-interstrand crosslinking agents. Mol Cancer 9: 127, 2010.

35. Shi F, Shi M, Zeng Z, et al: PD-1 and PD-L1 upregulation promotes CD8(+) T-cell apoptosis and postoperative recurrence in hepatocellular carcinoma patients. Int J Cancer 128: 887-896, 2011.

36. Chen J, Liu WB, Jia WD, et al: Overexpression of mortalin in hepatocellular carcinoma and its relationship with angiogenesis and epithelial to mesenchymal transition. Int $\mathrm{J}$ Oncol 44: 247-255, 2014

37. Montella L, Addeo R, Palmieri G, et al: Zoledronic acid in the treatment of bone metastases by hepatocellular carcinoma: a case series. Cancer Chemother Pharmacol 65: 1137-1143, 2010.

38. Crawford BA, Kam C, Pavlovic J, et al: Zoledronic acid prevents bone loss after liver transplantation: a randomized, double-blind, placebo-controlled trial. Ann Intern Med 144: 239-248, 2006.

39. Lu YR, Yuan Y, Wang XJ, et al: The growth inhibitory effect of mesenchymal stem cells on tumor cells in vitro and in vivo. Cancer Biol Ther 7: 245-251, 2008.

40. Wang SW, Wu HH, Liu SC, et al: CCL5 and CCR5 interaction promotes cell motility in human osteosarcoma. PLoS One 7: e35101, 2012.

41. Cambien B, Richard-Fiardo P, Karimdjee BF, et al: CCL5 neutralization restricts cancer growth and potentiates the targeting of PDGFR $\beta$ in colorectal carcinoma. PLoS One 6: e28842, 2011.

42. Vaday GG, Peehl DM, Kadam PA and Lawrence DM: Expression of CCL5 (RANTES) and CCR5 in prostate cancer. Prostate 66: 124-134, 2006. 
43. Gallo M, De Luca A, Lamura L and Normanno N: Zoledronic acid blocks the interaction between mesenchymal stem cells and breast cancer cells: implications for adjuvant therapy of breast cancer. Ann Oncol 23: 597-604, 2012.

44. Long H, Xie R, Xiang T, et al: Autocrine CCL5 signaling promotes invasion and migration of $\mathrm{CD}_{133^{+}}$ovarian cancer stem-like cells via NF- $\mathrm{B}$-mediated MMP-9 upregulation. Stem Cells 30: 2309-2319, 2012.

45. Barashi N, Weiss ID, Wald O, et al: Inflammation-induced hepatocellular carcinoma is dependent on CCR5 in mice. Hepatology 58: 1021-1030, 2013.

46. Orimo A, Gupta PB, Sgroi DC, et al: Stromal fibroblasts present in invasive human breast carcinomas promote tumor growth and angiogenesis through elevated SDF-1/CXCL12 secretion. Cell 121: 335-348, 2005.

47. Mo W, Chen J, Patel A, et al: CXCR4/CXCL12 mediate autocrine cell-cycle progression in NF1-associated malignant peripheral nerve sheath tumors. Cell 152: 1077-1090, 2013.

48. Liu H, Pan Z, Li A, et al: Roles of chemokine receptor 4 (CXCR4) and chemokine ligand 12 (CXCL12) in metastasis of hepatocellular carcinoma cells. Cell Mol Immunol 5: 373-378, 2008.

49. Li X, Yang Z, Song W, et al: Overexpression of Bmi-1 contributes to the invasion and metastasis of hepatocellular carcinoma by increasing the expression of matrix metalloproteinase (MMP)-2, MMP-9 and vascular endothelial growth factor via the PTEM/PI3K/Akt pathway. Int J Oncol 43: 793-802, 2013.
50. Suthiphongchai T, Promyart P, Virochrut S, Tohtong R and Wilairat P: Involvement of ERK1/2 in invasiveness and metastatic development of rat prostatic adenocarcinoma. Oncol Res 13: 253-259, 2003

51. Diaz-Gil JJ, Garcia-Monzon C, Rua C, et al: The anti-fibrotic effect of liver growth factor is associated with decreased intrahepatic levels of matrix metalloproteinases 2 and 9 and transforming growth factor beta 1 in bile duct-ligated rats. Histol Histopathol 23: 583-591, 2008.

52. Roomi MW, Kalinovsky T, Rath M and Niedzwiecki A: In vitro modulation of MMP-2 and MMP-9 in pediatric human sarcoma cell lines by cytokines, inducers and inhibitors. Int J Oncol 44: 27-34, 2014.

53. Xiang ZL, Zeng ZC, Fan J, et al: Gene expression profiling of fixed tissues identified hypoxia-inducible factor-1 $\alpha$, VEGF, and matrix metalloproteinase-2 as biomarkers of lymph node metastasis in hepatocellular carcinoma. Clin Cancer Res 17: 5463-5472, 2011.

54. Wang YH, Dong YY, Wang WM, et al: Vascular endothelial cells facilitated HCC invasion and metastasis through the Akt and NF- $\kappa \mathrm{B}$ pathways induced by paracrine cytokines. J Exp Clin Cancer Res 32: 51, 2013.

55. Gao J, Ding F, Liu Q and Yao Y: Knockdown of MACC expression suppressed hepatocellular carcinoma cell migration and invasion and inhibited expression of MMP2 and MMP9. Mol Cell Biochem 376: 21-32, 2013. 